\title{
Contrast effects and delay of reward in the double alleyway
}

JOSEPH A. SGRO, ROBERT A. GLOTFELTY, and JAMES A. PODLESNI, Virginia Polytechnic Institute, Blacksburg, Va. 24061

Four groups of albino rats received a factorial arrangement of contrasting rewards in $G 1$ ( 2 or 8 pellets) and $G 2$ ( 2 or 8 pellets) of a double alleyway. After 63 trials, each group was divided into two equal groups and shifted to either a 15-sec or 0-sec delay of GI reward. During preshift trials, a "depression" effect occurred in A1. During postshift trials, delay of $G 1$ reward inhibited Al speeds but had no effect on $A 2$ speeds. The results were interpreted as supporting the notion that the double alleyway may be considered as a differential conditioning situation. The postshift $A 2$ speed data were interpreted within the framework of frustration theory.

Daly (1968) has suggested that the double alley way is operationally similar to differen. tial conditioning situations (Bower, 1961) and that similar results could be expected from both. The "contrast effects" phenomenon has frequently been demonstrated in differential conditioning (Black, 1968). Two reward magnitudes experienced by the same $S$ results in performance that is a function of the contrast between the reward magnitudes. Specifically, enhanced performance or an "elation" effect is found when a larger reward is contrasted to a smaller reward. Inhibited performance or a "depression" effect, on the other hand, is found when a smaller reward is contrasted with a large reward. A review of double alleyway literature has revealed no experiment in which performance has been specifically studied as a function of contrasting first goalbox (G1) and second goalbox (G2) reward magnitudes. The present double alleyway study attempted to examine whether "elation" or "depression" effects could be obtained as a function of contrasting rewards in G1 (two or eight pellets) and G2 (two or eight pellets).

In addition, the present experiment provided information concerning the role of constant delay of reward in the double alleyway by shifting from immediate to a constant delay of $\mathrm{G} 1$ reward after extended training under contrasting $G 1$ and $G 2$ reward magnitudes.

\section{SUBJECTS}

The Ss were 88 male albino SpragueDawley rats, approximately $90-100$ days old at the beginning of the experiment. Two Ss

\section{died during the course of the experiment.} APPARATUS

The apparatus was an L-shaped double alleyway consisting of a first start box(SB), a first alleyway (A1), a first goalbox (G1), a second alleyway (A2), and a second goalbox (G2). The complete apparatus was 3 in. wide and $5 \mathrm{in}$. high throughout. The first start box and first alleyway were 10 in. and 36 in. in length, respectively. The first goalbox, which was $L$ shaped, was 13 in. long and the arm of the $L$ was $9 \mathrm{in}$. long. This goalbox also served as the start box for the second alleyway. A horizontal sliding delay door was located 3 in. from the guillotine door which separated G1 from A2. Sections A2 and $G 2$ were 72 in. and 14 in. in length, respectively. The second goalbox was also $L$ shaped and was $11 \mathrm{in.} \mathrm{in} \mathrm{length} \mathrm{at} \mathrm{the} \mathrm{arm}$ of the L. Guillotine doors separated SB from $A 1, A 1$ from $G 1, G 1$ from $A 2$, and $A 2$ from G2. The entire apparatus was covered with 1/8-in. Plexiglas and was constructed of 3/4-in. plywood. Sections SB, A1, and G1, as well as the guillotine doors opening into $A 1$ and G1, were painted flat black. Sections $A 2, G 2$, and the guillotine doors opening into $A 2$ and $G 2$ were painted flat white. The floor of $A 1$ and $G 1$ was covered with a black rubber mat. The entire apparatus was illuminated by $7-W$ bulbs suspended 20 in. above the Plexiglas.

Start times for Al were measured from the opening of the SB door to the breaking of a photobeam 3 in. distant. Running times for $A 1$ were measured from the breaking of a beam 3 in. distant from the SB door to the interruption of a second beam 36 in. distant. Start times for A2 were measured from the opening of the $\mathrm{G} 1$ door leading into A2 until the breaking of a photobeam 3 in. distant. Running times for $\mathrm{A} 2$ were measured from the breaking of the latter photobeam to the interruption of a second beam 72 in. distant.

Noyes $45-\mathrm{mg}$ food pellets were available to $S$ in a plastic cup between the sliding delay door and the guillotine door separating $G 1$ from $A 2$ and in a small bottle cap in G2.

\section{EXPERIMENTAL DESIGN}

The Ss were randomly assigned to four preshift groups $(\mathrm{N}=22)$ and received the following number of 45 -mg Noyes pellets in G1 and $G 2$, respectively: $2-2,2-8,8-8$, and 8-2. After 63 trials of training, each of the treatment groups was divided into two groups $(\mathrm{N}=11)$ by a quasi-random fashion based on A2 start times; they received a 0 -sec and a 15-sec delay of G1 reward, respectively, for 45 trials. Delay groups were designated as 2D-2, 2D-8, 8D-8, and 8D-2. PROCEDURE

Fourteen days prior to the first preshift day, Ss were placed on a $22 \% / 2-h$ fooddeprivation schedule. During this period each $S$ was gentled for approximately $5 \mathrm{~min}$ daily. On Days 13 and 14, each $S$ was allowed to explore the entire apparatus for $2 \mathrm{~min}$ and then was given two 45-mg Noyes pellets in a holding cage before being returned to the home cage. On Days 1 and 2 of training, $S$ was given one trial, on Days 3 and 4, two trials, and three trials a day thereafter. The intertrial interval was approximately $1 \mathrm{~min}$. A training trial was initiated with the placing of $S$ in to the $S B$. Five seconds later, $E$ raised the guillotine door, allowing $S$ to traverse Al. Upon entering $\mathrm{Gl}$, the guillotine door was lowered to prevent retracing and $S$ was allowed to eat the available pellets. Upon completion of the eating and as soon as $\mathrm{S}$ was oriented to the guillotine door opening to $A 2, E$ raised the door and $S$ was allowed to traverse $A 2$. Test trials involved the same procedure except that for groups experiencing delay, the delay door in G1 remained closed for $15 \mathrm{sec}$ after the interruption of the photobeam located in G1.

RESULTS

Starting and running time measures for each trial were converted into speed scores (ft/sec) and all analyses were performed using the converted scores. Four measures of performance were recorded: start and running times for $\mathrm{Al}$ and start and running times for $\mathrm{A} 2$.

\section{Preshift Phase}

Alley 1. Mean A1 start and running speeds over blocks of nine trials are shown in Fig. 1. It should be noted from Fig. 1 that the running measure was more affected by G2 reward magnitude than the start measure. Analyses of variance over the seven blocks of trials yielded a significant G1 reward magnitude effect for both start speeds $(F=10.51, \mathrm{df}=1 / 82, \mathrm{p}<.01)$ and running speeds $(F=27.33$, df $=1 / 82$, $p<.01$ ). Magnitude of $G 2$ reward, however, influenced $A 1$ running speeds $(F=6.79$, df $=1 / 82, p<.05)$, but not start speeds $(F<1$, df $=1 / 82)$. The G1 by G2 Reward Magnitude interaction failed to achieve significance for either measure (Fs $<1$, $\mathrm{df}=1 / 82$ ). Orthogonal comparisons of treatment sums revealed that Group 2.8 ran significantly slower than Group 2-2 over the running measure $(F=4.00, d f=1 / 82$, $\mathrm{p}<.05$ ), but not significantly different over the start measure $(F=1.26, \mathrm{df}=1 / 82)$. Groups $8-2$ and 8.8 failed to yield reliable differences in either start speeds $(F<1$, $\mathrm{df}=1 / 82)$ or running speeds $(F=2.87$, $\mathrm{df}=1 / 82$ ).

Alley 2. Mean A2 start and running speeds over blocks of nine trials are 

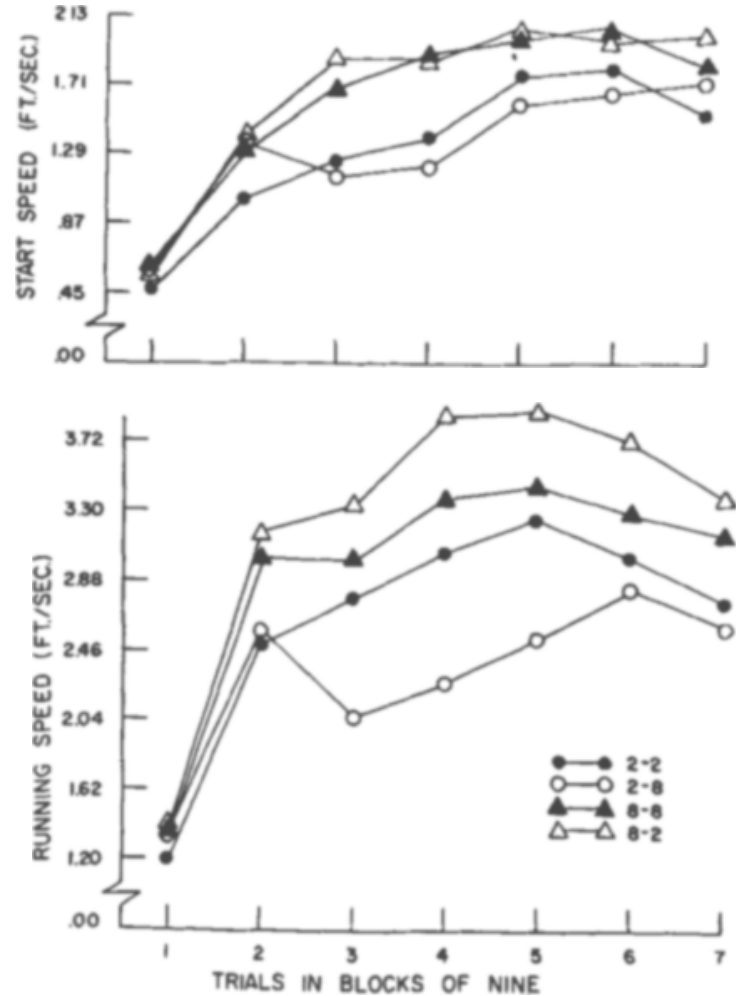

Fig. 1. Mean Al start and running speeds in blocks of nine trials during the preshift phase.
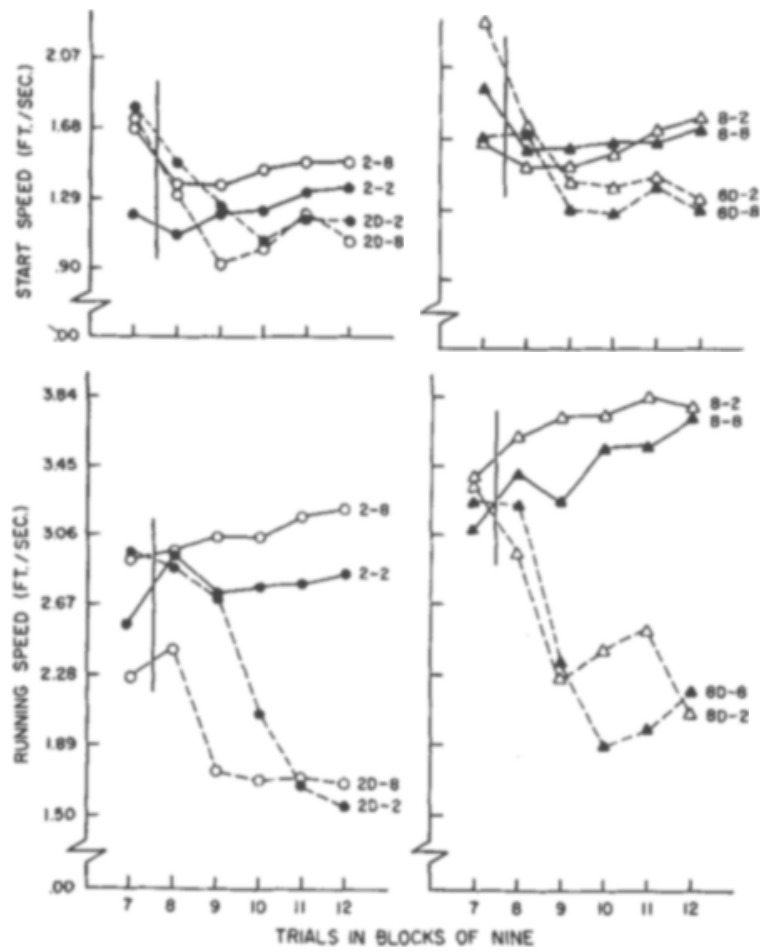

Fig. 3. Mean Al start and running speeds in blocks of nine trials during the postshift phase. (Block 7 represents the mean of the last nine preshift trials.)

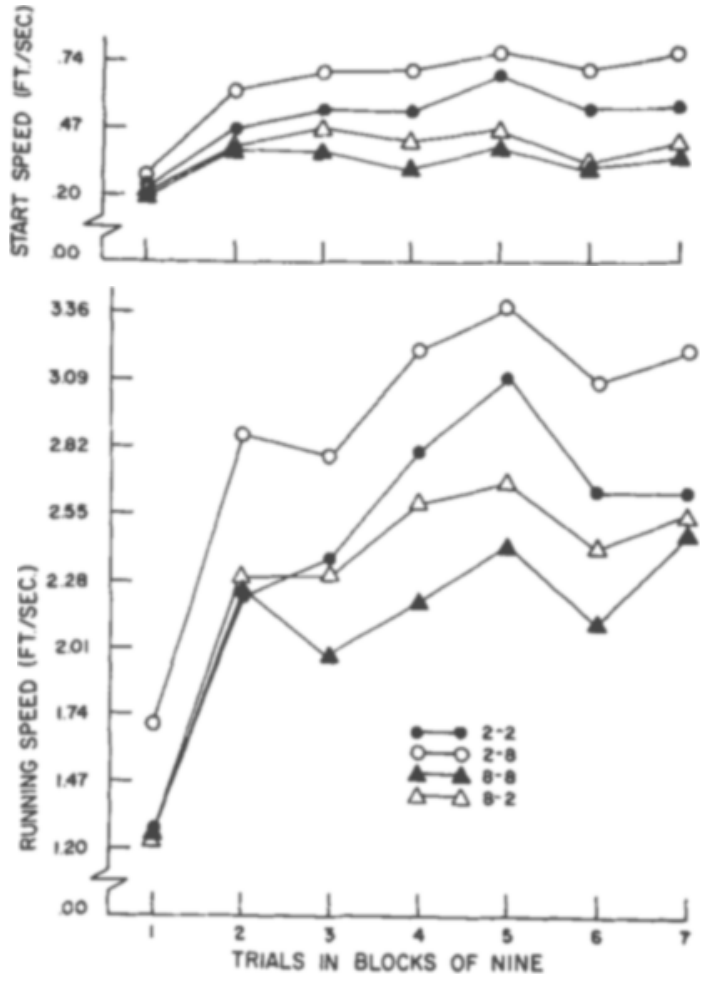

Fig. 2. Mean A2 start and running speeds in blocks of nine trials during the preshift phase.
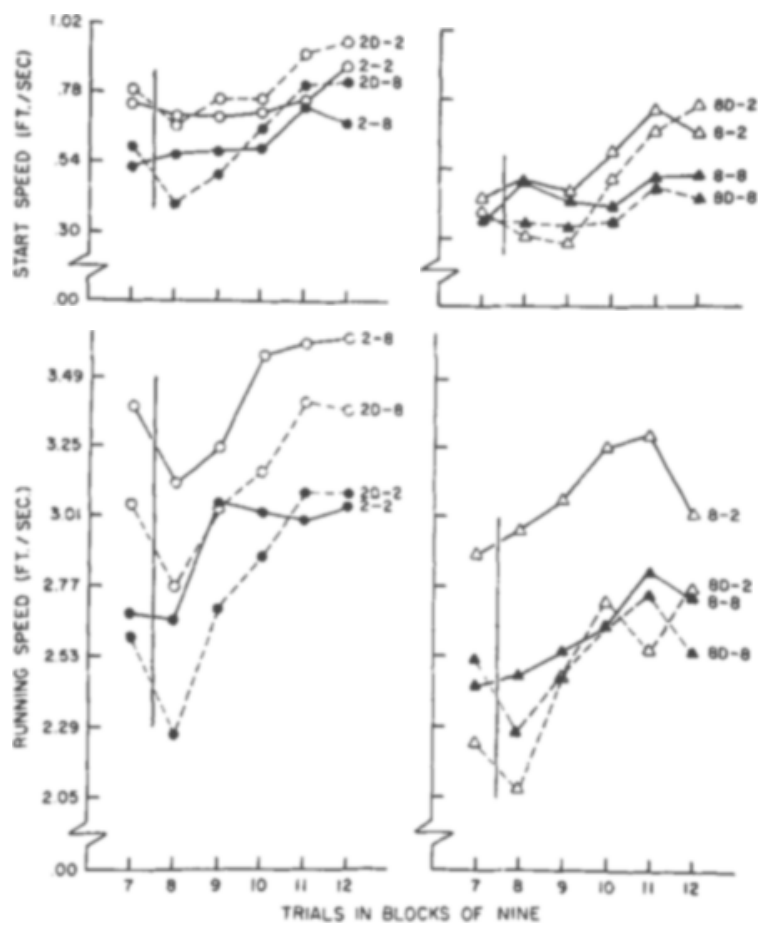

Fig. 4. Mean A2 start and running speeds in blocks of nine trials during the postshift phase. (Block 7 represents the mean of the last nine preshift trials.) 
presented in Fig. 2. It is apparent from Fig. 2 that groups experiencing two pellets in $G 1$ were performing at a higher level than groups receiving eight pellets. Analysis of variance over the seven blocks of preshift trials indicated that the $G 1$ reward magnitude variable was statistically reliable for both start speeds $(F=18.06, d f=1 / 82$, $p<.01)$ and running speeds $(F=14.60$, $\mathrm{df}=1 / 82, \mathrm{p}<.01$ ). The magnitude of $\mathrm{G} 2$ reward, however, failed to affect either the start measure $(\mathrm{F}<1, \mathrm{df}=1 / 82)$ or the running measure $(F=1.10, \mathrm{df}=1 / 82)$. It was further revealed that the $G 1$ by $G 2$ Reward Magnitude interaction achieved significance at the .10 level for the start speeds $(F=3.20, \mathrm{df}=1 / 82)$ and at the .01 level for the running speeds $(F=7.17$, $\mathrm{df}=1 / 82$ ). Orthogonal comparisons of treatment sums indicated that Group 2-8 ran faster than Group 8.8 for both the start measure $(F=18.26, \mathrm{df}=1 / 82, \mathrm{p}<.01)$ and the running measure $(F=21.09, \mathrm{df}=1 / 82$, $\mathrm{p}<.01$ ). Group $8-2$ was not statistically different from Group 2.2 for either the start measure $(\mathrm{F}=2.94, \mathrm{df}=1 / 82)$ or the running measure $(\mathrm{F}<1, \mathrm{df}=1 / 82)$.

\section{Postshift Phase}

Alley 1. Mean Al start and running speeds over blocks of nine trials are shown in Fig. 3. As may be observed, the introduction of delay in G1 produced an immediate decline in both Al start and running speeds. Analyses of variance over the five blocks of test trials indicated that delay significantly disrupted start speeds $(F=5.90, \mathrm{df}=1 / 78$, $\mathrm{p}<.05)$ and running speeds $(\mathrm{F}=62.62$, $\mathrm{df}=1 / 78, \mathrm{p}<.01)$. The $\mathrm{G} 1$ reward magnitude variable was significant in both start and running speeds $(F=13.41,14.78$, respectively, $\mathrm{df}=1 / 78, \mathrm{p}<.01)$. None of the other interactions were significant.

Alley 2. Mean A2 start and running speeds over blocks of nine trials are given in Fig. 4. With the exception of the start speeds for groups receiving two pellets in $\mathrm{Gl}$, all no-delay groups showed superior performance to that of the delayed groups. Analyses of variance performed over the five blocks of postshift trials indicated that the effect of $\mathrm{G} 1$ reward was statistically reliable for start speeds $(\mathrm{F}=17.64, \mathrm{df}=1 / 78$, $p<.01)$ and running speeds $(F=9.14$, $\mathrm{df}=1 / 78, \mathrm{p}<.01)$. The $\mathrm{G} 2$ reward magnitude variable was not significant for either the start or running measures (Fs $<1$, $\mathrm{df}=1 / 78$ ). Delay of $\mathrm{Gl}$ reward did not reliably affect start speeds $(F<1$, $\mathrm{df}=1 / 78)$, but did significantly reduce run speeds $(F=4.85$, df $=1 / 78, p<.05)$. The G1 by G2 Reward Magnitude interaction was significant for both start and run measures $(F=6.25,4.85$, respectively, $\mathrm{df}=1 / 78, p<.05)$. None of the other interactions were significant.

\section{DISCUSSION}

The present data lend support to the notion that as a consequence of the similarity in operations, the double alleyway should yield behavioral phenomena which resemble those obtained under differential conditioning situations with contrasting reward magnitudes. The major finding which related to the "depression" effect was the slower preshift Al running speeds of Group 2-8 relative to Group 2-2. An "elation" effect, i.e., faster Al speeds for Group 8-2 relative to Group 8-8, failed to occur. The results are seemingly in agreement with the literature in differential conditioning and in particular with an experiment by Matsumoto reported by Black (1968). With contrasting rewards in two separate alley ways, Matsumoto was able to obtain a "depression" effect but not an "elation" effect. The A2 results were not amenable to a contrast interpretation since it may also be claimed that "elation" or "depression" effects could be obtained on the basis of demotivation due to G1 reward (Seward, Pereboom, Butler, \& Jones, 1957).

The effects of constant delay of $\mathrm{Gl}$ reward on $A 2$ performance do not support Amsel's (1958) implication that delay of G1 reward may be interpreted as a frustrative event. To this end, it would be expected that A2 performance should be facilitated by the shift to delay of $\mathrm{G} 1$ reward. The present data confirm results reported by McHose (1966) who found that in a within-S design, delay of G1 solid food reward did not enhance A2 performance. Within the Amsel theoretical framework, it might be expected that a shift to a constant G1 delay would create an interference of previously conditioned anticipatory goal responses $\left(r_{g}\right)$ with delay-engendered conditioned an ticipatory frustration responses $\left(r_{g}\right)$ in Al. In Fig. 3, the rapid decline of $\mathrm{A} 1$ speeds upon shift to delay would seem to support this contention. Amsel (1958) has assumed that enhanced $A 2$ performance due to frustrative nonreward in $G 1$ is contingent upon the strength of the conditioned $r_{g}$ in $A l$. It might therefore be expected that as a consequence of its rather immediate decremental effects on Al performance, a sudden shift to constant delay of $G 1$ reward would not result in facilitated A2 performance.

\section{REFERENCES}

AMSEL, A. The role of frustrative nonreward in noncontinuous reward situations. Psy chological Bulletin, 1958, 55, 102-119.

BLACK, R. W. Shifts in magnitude of reward and contrast effects in instrumental and selective learning: A reinterpretation. Psychological Review, 1968, 75, 114-126.

BOWER, G. H. A contrast effect in differential conditioning. Journal of Experimental Psychology, 1961, 62, 196-199.

DALY, H. B. Excitatory and inhibitory effects of complete and incomplete reward reduction in the double runway. Joumal of Experimental Psychology, 1968, 76, 430-438.

McHOSE, J. H. Delay increase and subsequent responding. Psychonomic Science, 1966, 5, 213-214.

SEWARD, J. P., PEREBOOM, A.C., BUTLER, B., \& JONES, R. B. The role of prefeeding in an apparent frustration effect. Journal of Experimental Psychology, 1957, 54, 445-550.

\section{The magnitude of the frustration effect as a function of the number of previously reinforced trials'}

\section{THERON STIMMEL and PHILLIP C ADAMS, University of Houston, Houston, Tex. 77004}

Responding in a double runway following the cessation of reinforcement in the first goalbox was studied as a function of either 35 or 75 prior reinforcements in the first goalbox. Second runway speeds showed a greater increase for the 75-reinforcement group. Results were discussed in terms of frustration theory.

A common, if not universal, finding in the animal learning literature is a nonmonotic relationship between number of reinforced trials and subsequent resistance to extinction. Both North \& Stimmel (1960) and Birch (1961) have employed Amsel's (1958) concept of frustration to account for this nonmonotonicity. According to Amsel, $\mathrm{r}_{\mathrm{f}} \mathrm{s}_{\mathrm{f}}$ (frustration) varies as a function of the level of $r_{g}-s_{g}$. Birch (1961) hypothesizes that at high levels of $r_{g}-s_{g}$ cessation of reinforcement leads to the elicitation of $\mathrm{I}_{\mathrm{f}}-\mathrm{s}_{\mathrm{f}}$ of sufficient magnitude to cause emotional responses incompatible with instrumental responding. This formulation, of course, 